\title{
PROTEÇÃO DE SISTEMAS FLUVIAIS EM UMA PERSPECTIVA GEOMORFOLÓGICA APLICADA AO VALE PRINCIPAL DA BACIA DO RIO BENEVENTE - ES
}

\author{
José Mario Leal Martins Costa ${ }^{(a)}$ \\ (a) Prof. Assistente do Curso de Geografia da Universidade Federal da Fronteira Sul/RS, jose.costa@uffs.edu.br \\ Doutorando em Geografia pela Universidade Federal do Rio Grande do Sul.
}

Eixo: Uso e ocupação das terras e legislação ambiental

\begin{abstract}
Resumo
O presente trabalho trata da análise geomorfológica focada na proteção dos cursos d'água e sistemas fluviais orientada às políticas públicas ambientais, tendo por base o questionamento quanto a eficácia do modelo vigente estabelecido pelo Código Florestal brasileiro através das Áreas de Preservação Permanente, tal como se apresenta na atualidade. O estudo abarcou a bacia hidrográfica do rio Benevente, situado no litoral sul do Estado do Espírito Santo, e deu-se através da análise de perfis transversais e longitudinais do rio principal mediante o emprego de técnicas de geoprocessamento, e através das informações geomorfológicas apresentadas no Projeto RADAMBRASIL, Folha SF 23/24. De modo geral, o estudo reforçou a percepção de que a proteção demandada para os sistemas fluviais de uma bacia hidrográfica aumenta no sentido de montante.
\end{abstract}

Palavras chave: Geomorfologia; Proteção de sistemas fluviais; APPs.

\section{Introdução}

Inúmeros estudos, no transcurso do tempo, desenvolvidos em diferentes países, ocuparam-se em demonstrar a importância da proteção dos sistemas fluviais, e apresentar diversos meios sugeridos para atingir esta finalidade. Muitos destes estudos foram, e continuam sendo, desenvolvidos no âmbito governamental de alguns países para balizar as políticas ambientais públicas direcionadas à proteção dos cursos d'água. No Brasil, o mecanismo de proteção equivalente surgiu a partir da edição do Código Florestal de 1965, através do instituto legal “Área de Preservação Permanente” (APP), que estabelece, entre outras tipologias, faixas métricas de restrição ao uso no entorno dos corpos d'água. Este modelo legal, entretanto, tem sido objeto de inúmeras críticas por parte dos pesquisadores das academias e das instituições públicas ambientais, visto que se resume a uma delimitação rígida, com força de lei, de faixas de preservação com larguras variáveis conforme a largura do curso d'água ao qual estão adjacentes.

Neste âmbito, Attanasio et al (2006) expõe que os ecossistemas marginais aos cursos d'água não podem ser integralmente mantidos apenas com o seu isolamento físico, sendo também necessário a adoção de práticas sustentáveis no seu entorno. Neste mesmo sentido, Moro (2006) e Machado (2002) reforçam que 
a implantação apenas de matas ciliares para a proteção dos cursos d'água não é suficiente sem o devido controle sobre os modelos de uso do solo e o combate aos processos erosivos.

Além da importância na intervenção do uso e da cobertura do solo nas imediações dos corpos d'água, é preciso também considerar as peculiaridades de cada porção espacial, tanto no aspecto físico, como social, na identificação do modo mais efetivo de proteção dos sistemas fluviais, principalmente nas condições de um país de dimensões continentais, como no caso brasileiro (COSTA, 2013). Neste viés, Momoli (2006) coloca que o modelo vigente de APP não considera as distintas realidades do território nacional, e, portanto, não se ajusta às condições e processos específicos que ocorrem localmente.

Em pesquisa antecedente sobre o tema efetuada por este autor, foi feita uma análise teórica sobre os aspectos pertinentes à geomorfologia na indicação de uma proteção mais efetiva dos sistemas fluviais (COSTA, 2010), tendo em mente as considerações críticas ao modelo de proteção dos cursos d'água no Brasil por intermédio das APPs, e as diversidades de ambientes e paisagens que podem ser propiciadas, entre outros, a partir das conformações do relevo. A partir de tal, foi concluído que, ao contrário do que se verifica nas disposições do Código Florestal, onde as faixas de APP acrescem para jusante conjuntamente ao alargamento dos cursos d'água, as necessidades de proteção, tanto no contexto geomorfológico como no ecológico, aparentam um maior apelo no sentido de montante, reportando para as áreas de abastecimento do aqüífero, onde o relevo tende a ser mais acidentado, e a produção de sedimentos maior.

O presente trabalho tem por fim a execução de um estudo de caso, através da análise de parâmetros morfométricos e morfológicos para o vale do rio Benevente, como um exercício simplificado, visando averiguar e comprovar as conclusões obtidas teoricamente em Costa (2010), ou seja, a de que a necessidade de proteção dos sistemas fluviais intensifica-se para montante, principalmente quando são consideradas as conformações do relevo no Sudeste brasileiro.

\section{2. Área de estudo}

A bacia do rio Benevente possui uma área de drenagem de aproximadamente $1.207 \mathrm{~km} 2$, e está situada na região do litoral sul do Estado do Espírito Santo, Abrangendo os municípios de Anchieta, Alfredo Chaves, Iconha, Guarapari e Piúma. As atividades econômicas de região giram em torno da pecuária, da agricultura (principalmente a cafeicultura), e da indústria, havendo também forte participação do turismo e da pesca nas porções litorâneas. Os principais problemas socioambientais verificados na bacia decorrem do acelerado processo de ocupação do solo, promovendo o desenvolvimento de processos erosivos nas encostas, e os impactos negativos efetuados sobre os cursos d'água, desprovidos de matas ciliares, e que sofrem com o lançamento de efluentes e resíduos sólidos (IEMA, 2016). 


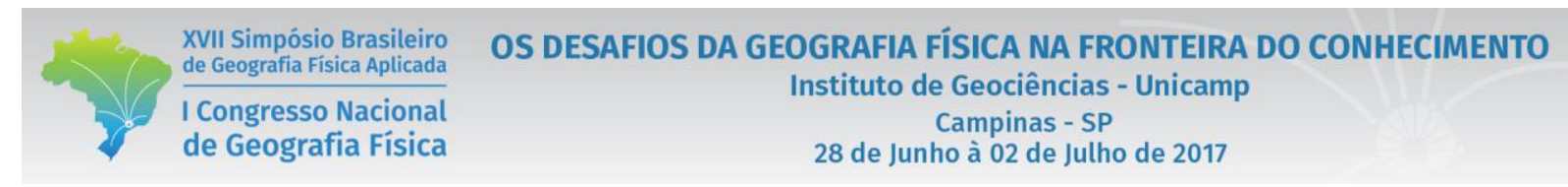

Em termos geológicos, a bacia abarca, em sua grande maioria, o Complexo Paraíba do Sul, que constitui parte do embasamento do Cinturão Móvel do Atlântico, e apresenta uma litologia predominante de gnaisses granatíferos e kinzigitos. Em meio a este Complexo encontram-se intrusões graníticas que integram a denominada "Suíte Intrusiva Espírito Santo", dos quais se destaca a Suíte Bela Joana, composta por rochas enderbíticas e charnockíticas, sendo uma subunidade do Complexo Paraíba do Sul disposta na porção leste, de Campos dos goytacazes - RJ até o sudeste do Estado do Espírito Santo (RADAMBRASIL, 1983; CPRM, 2016).

A Geomorfologia da bacia do rio Benevente é dado pelos agrupamentos taxonômicos definidos no mapeamento do Projeto RADAMBRASIL (1983), conforme apresentado na tabela I.

Tabela I - Agrupamentos geomorfológicos, por níveis taxonômicos, presentes na bacia do rio

\begin{tabular}{llll}
\hline $\begin{array}{c}\text { Domínios } \\
\text { Morfoestruturais }\end{array}$ & \multicolumn{1}{c}{$\begin{array}{c}\text { Regiões } \\
\text { Geomorfológicas }\end{array}$} & \multicolumn{1}{c}{$\begin{array}{c}\text { Bnidades } \\
\text { Geomorfológicas }\end{array}$} & Modelados \\
\hline \multirow{2}{*}{$\begin{array}{l}\text { Colinas e Maciços } \\
\text { Costeixas de Dobramentos }\end{array}$} & $\begin{array}{l}\text { Colinas e Maciços } \\
\text { Costeiros } \\
\text { Remobilizados }\end{array}$ & $\begin{array}{l}\text { Pantiqueires Escalonados } \\
\text { do sul capixaba }\end{array}$ & D1, Dg2, Dm2 \\
& Setentrional & $\begin{array}{l}\text { Maciços do Caparaó } \\
\text { Planícies Litorâneas e } \\
\text { Depósitos Sedimentares }\end{array}$ & D2 \\
& Planícies Costeiras & Af \\
& Tabuleiros Costeiros & Tabuleiros Costeiros & Dm \\
\hline & Fonte: Adaptado de RADAMBRASIL, 1983. &
\end{tabular}

\section{Metodologia}

O trabalho consistiu no emprego de técnicas de geoprocessamento para a análise dos aspectos físicos da bacia do rio do Benevente, e para a geração de perfis topográficos de secções transversais de alguns pontos ao longo do curso d'água, bem como de perfis longitudinais do rio Benevente e de segmentações deste. Para este fim foi utilizado o software Quantum GIS 1.8.0 para a análise dos dados e a confecção dos mapas (Sistema de Coordenadas UTM / SIRGAS 2000), e o Plugin Profile Tool do QGIS para a geração dos perfis topográficos. Os dados de hipsometria (com eqüidistância de 20 metros), hidrografia, e de delimitação da bacia hidrográfica foram obtidos através do Instituto Estadual de Meio Ambiente do Estado do Espírito Santo - IEMA (2016). Os dados da geologia foram obtidos através de informações tanto do Projeto RADAMBRASIL (1983) como dos mapeamentos da CPRM (2016).

Os dados da geomorfologia foram obtidos através do georreferenciamento e da vetorização de mapas do Projeto RADAMBRASIL. Neste procedimento foram geradas duas camadas referentes à geomorfologia: uma apresentando as delimitações dos Domínios, Regiões e Unidades Geomorfológicas na área da bacia; e, outra apresentando os tipos de Modelados para cada Unidade Geomorfológica (Figura 1). 


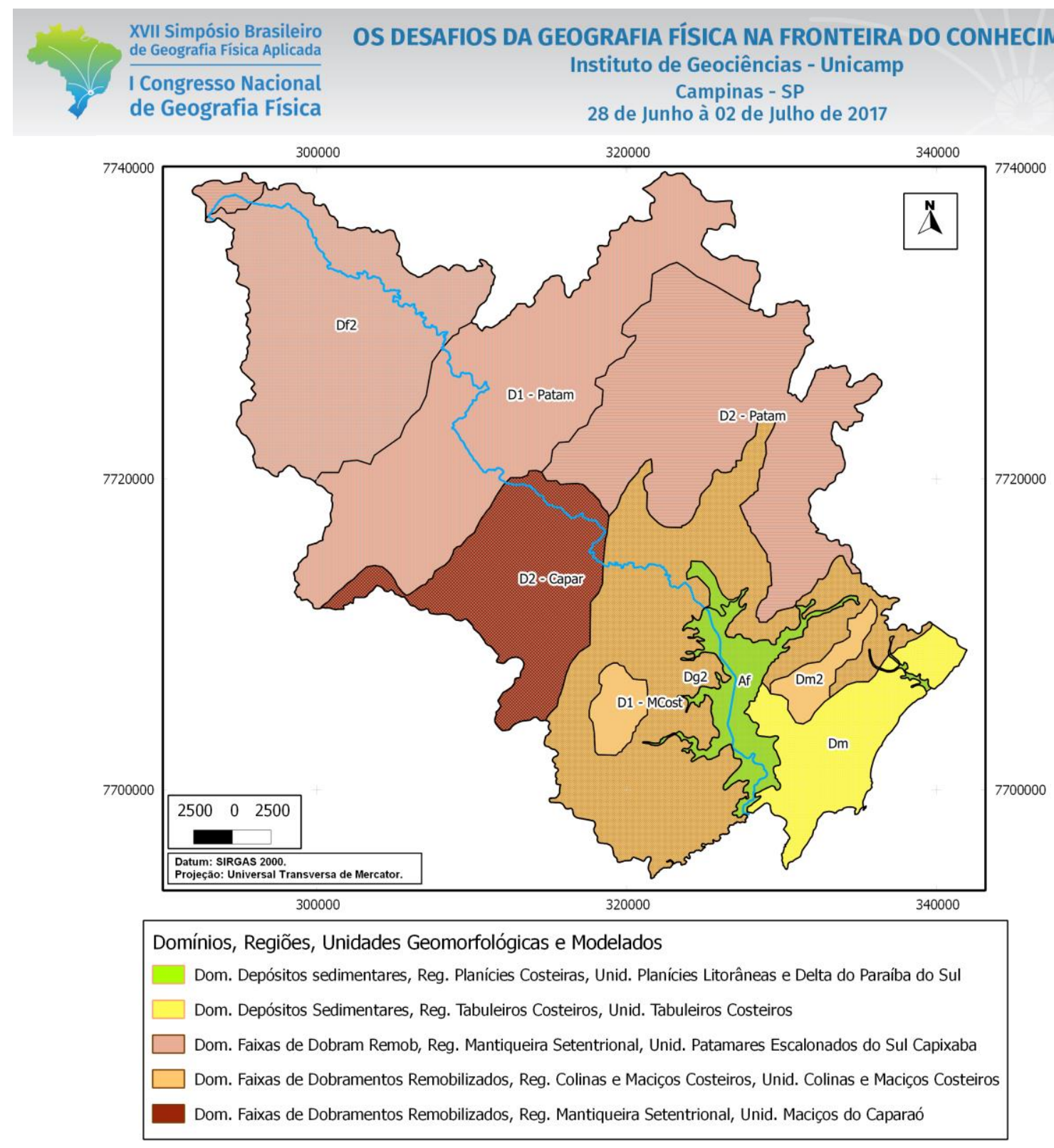

Figura 1 - mapa geomorfológico da bacia do rio Benevente, conforme classificação do RADAMBRASIL, 1983.

Através do arquivo vetorial de hipsometria foi gerado o arquivo do Modelo Digital de Elevação (MDE) no formato raster, e através deste, foi gerado o mapa de declividade e o mapa de relevo da bacia.

Havendo o interesse específico nos processos e nas conformações do vale do rio principal da bacia, foi gerada uma camada vetorial com o traçado do rio Benevente a partir do arquivo de hidrografia do IEMA. A partir daquela camada e das referentes à hipsometria e à geomorfologia foi criada uma camada onde foram delineados os transectos a serem analisados no transcurso do rio. Foram definidos 20 transectos (Figura 2) abarcando todas as Unidades Geomorfológicas internas à bacia do Benevente e os seus Modelados, bem como os limites entre os mesmos. 


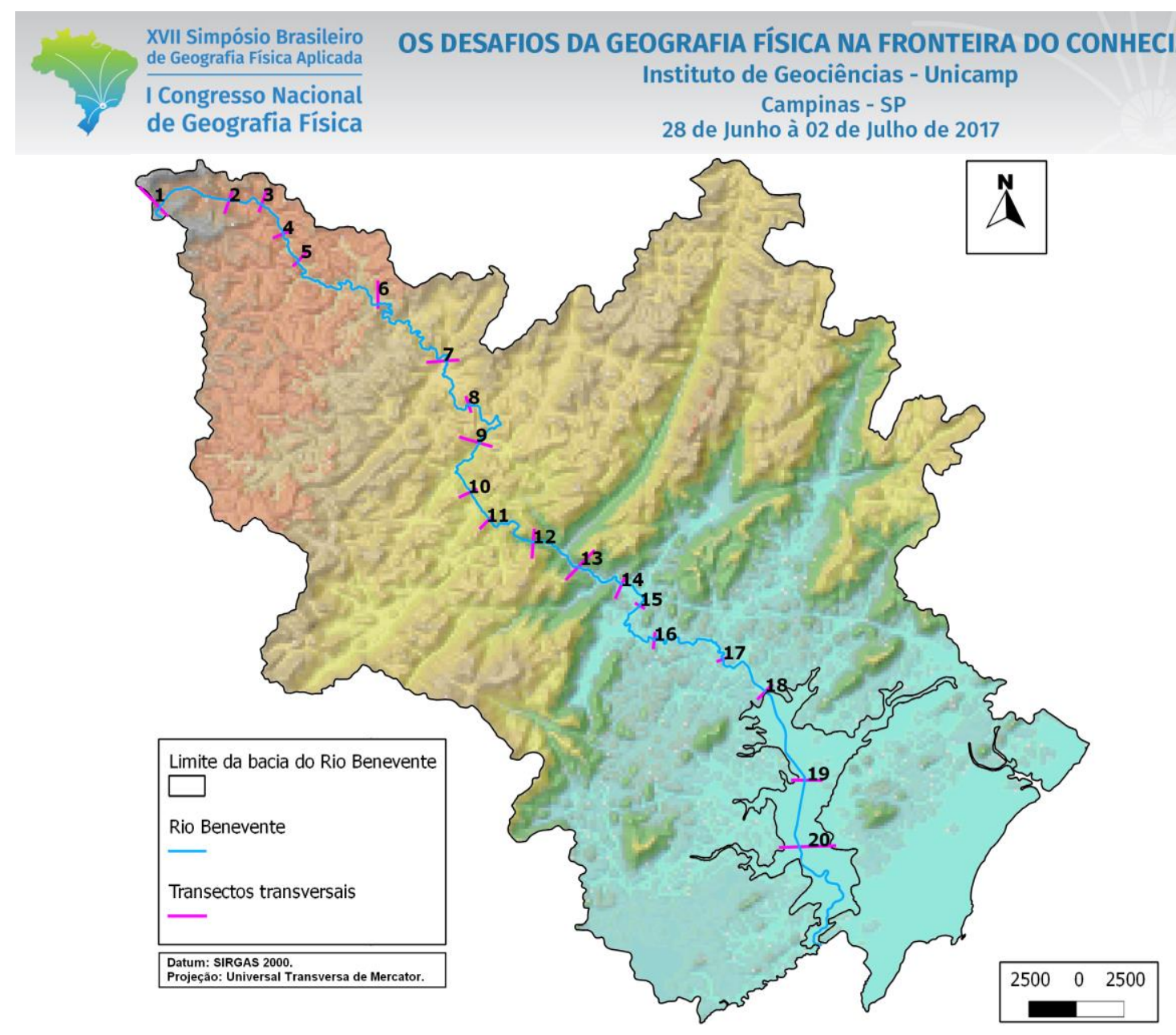

Figura 2 - Mapa de relevo da bacia do rio Benevente, com as posições dos transectos transversais ao curso principal.

Para atingir o objetivo do trabalho, considerou-se estipular uma caracterização genérica dos tipos de relevos ao longo do rio Benevente, especificando as conformações dos vales em consonância com a natureza dos substratos que sustentam as suas formas, e os processos responsáveis pelas suas esculturações. Neste aspecto, buscou-se associar cada transecto com as classes de rugosidade do relevo nos quais estavam inseridos, justamente por ser "de fácil uso e compreensão por outros especialistas não geomorfólogos" (FLORENZANO, 2008), indicando ainda a profundidade média de dissecação (D) dos vales naqueles transectos e as declividades registradas em suas vertentes. O intuito desta prática é o de tentar avaliar os níveis de fragilidade na conjuntura dos transectos dos vales observados, e os níveis de restrição quanto ao uso (ou ao tipo de cobertura do solo) para cada qual, e assim identificar qualitativamente os níveis de proteção requeridos nos segmentos do curso do rio Benevente.

As profundidades médias de dissecação dos vales foram calculadas através da média aritmética das altitudes dos interflúvios, subtraídas dos valores de cotas dos fundos de vale. 


\section{OS DESAFIOS DA GEOGRAFIA FÍSICA NA FRONTEIRA DO CONHECIMENTO \\ Instituto de Geociências - Unicamp \\ Campinas - SP \\ 28 de Junho à 02 de Julho de 2017}

As classes de rugosidade do relevo foram definidas de acordo com o apresentado na tabela II, e as classes de declividade de acordo com a tabela III, sendo os mesmos utilizados para a indicação da capacidade de uso/aptidão agrícola e nos levantamentos geotécnicos.

Tabela II - Classes de relevo e aspectos morfológicos e morfométricos associados.

\begin{tabular}{|c|c|c|c|c|}
\hline \multirow[t]{2}{*}{ Classe de relevo } & \multirow[t]{2}{*}{ Formas associadas } & \multirow[t]{2}{*}{ Topos } & \multicolumn{2}{|c|}{ Vertentes } \\
\hline & & & Formas & $\begin{array}{c}\text { Declividades } \\
(\%)\end{array}$ \\
\hline Plano & Planícies, terraços, tabuleiros. & Planos & - & $<3$ \\
\hline Suave Ondulado & Colinas, outeiros. & $\begin{array}{l}\text { Arredondados /ou } \\
\text { planos }\end{array}$ & $\begin{array}{l}\text { Planas e } \\
\text { convexas }\end{array}$ & 3 a 8 \\
\hline Ondulado & Colinas, outeiros, morrotes. & Arredondados & Convexas & 8 a 20 \\
\hline Forte Ondulado & Outeiros, morros, serras. & $\begin{array}{l}\text { Arredondados } \\
\text { e/ou angulosos }\end{array}$ & $\begin{array}{l}\text { Convexas } \\
\text { e côncavas }\end{array}$ & 20 a 45 \\
\hline Montanhoso & $\begin{array}{l}\text { Morros, montanhas, maciços e } \\
\text { alinhamentos montanhosos }\end{array}$ & Angulosos & Côncavas & 45 a 75 \\
\hline Escarpado & Abruptos e escarpas & - & - & $>75$ \\
\hline \multicolumn{5}{|c|}{ Fonte: Adaptado de FLORENZANO, 2008; GUERRA, 2005.} \\
\hline \multicolumn{5}{|c|}{ Tabela III - Classes de declividade. } \\
\hline & Categorias & $\%$ & & \\
\hline & Muito Fraca & Até 6 & & \\
\hline & Fraca & 6 a 12 & & \\
\hline & Média & 12 a 20 & & \\
\hline & Forte & 20 a 30 & & \\
\hline & Muito Forte & Acima de 30 & & \\
\hline
\end{tabular}

Já os aspectos que traduzem as características geomorfológica específicas da região, tanto no estrutural como no escultural, foram balizados nos agrupamentos sucessivos dos táxons definidos e mapeados pelo Projeto RADAMBRASIL (1983), sendo assim dispostos por ordem de grandeza espacial e temporal: Domínios Morfoestruturais, Regiões Geomorfológicas, Unidades Geomorfológicas, e Modelados.

\section{Resultados}

Os dados morfométricas dos vales onde foram delineados os transectos transversais, e as características morfológicas dos relevos onde aqueles estão inseridos estão sumarizados na tabela IV. 


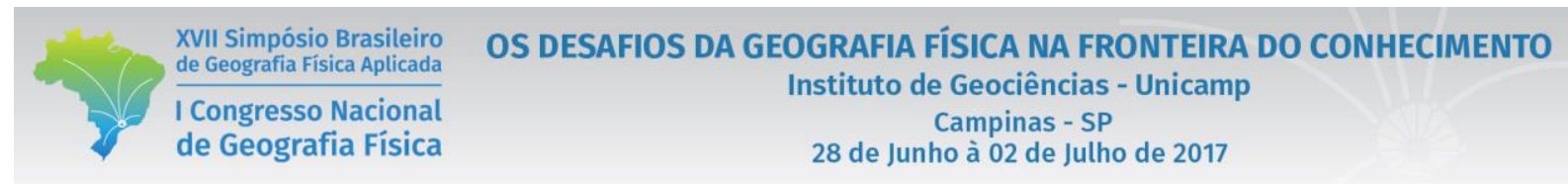

Tabela IV - Caracterização morfológica dos transectos indicados no mapa da imagem 2.

\begin{tabular}{|c|c|c|c|c|}
\hline Transectos & $\begin{array}{c}\text { Profundidades } \\
\text { médias dos vales - } \\
\text { D (m). }\end{array}$ & $\begin{array}{l}\text { Intervalos de } \\
\text { Declividades } \\
(\%)\end{array}$ & $\begin{array}{l}\text { Categorias de } \\
\text { declividades }\end{array}$ & Classes de relevos \\
\hline 1,2 e 3 & De 300 a 220 & Entre 25 e $48 \%$ & Forte a muito forte & Forte ondulado a montanhoso \\
\hline 4 e 5 & De 130 a 180 & Entre 21 e $34 \%$ & Forte a muito forte & Forte ondulado \\
\hline 6 e 7 & De 90 a 180 & Entre 20 e $48 \%$ & Forte a muito forte & Forte ondulado \\
\hline 8,9 e 10 & De 150 a 230 & Entre 17 e $37 \%$ & Forte a muito forte & Forte ondulado \\
\hline 11,12 e 13 & De 230 a 430 & Entre 25 e $75 \%$ & Forte a muito forte & Forte ondulado a montanhoso \\
\hline 14 & 130 & Entre 15 e $36 \%$ & Média a muito forte & Forte ondulado a ondulado \\
\hline 15 e 16 & 50 & Entre 6 e $16 \%$ & Fraca a média & Suave ondulado a ondulado \\
\hline 17 e 18 & 40 & Entre 5 e $12 \%$ & Muito fraca a fraca & Suave ondulado a ondulado \\
\hline 19 e 20 & De 40 a 20 & Entre 2 e $6 \%$ & Muito fraca & Suave ondulado a plano \\
\hline
\end{tabular}

Notoriamente, pode-se observar que os transectos do curso superior apresentam vertentes com declives acentuados, em vales consideravelmente dissecados, situados sobre terrenos forte ondulados a montanhosos, havendo paulatina redução nas dimensões dos interflúvios, com conseqüente diminuição no grau de dissecação dos vales e nas declividades das vertentes, conforme se analisa os transectos em direção ao baixo curso (para jusante). Da mesma forma, evidencia-se que os processos erosivos atuantes sobre as encostas, e que interferem na dinâmica dos sistemas fluviais e nas qualidades das águas, são mais intensos à montante, requerendo um controle maior sobre as técnicas e naturezas dos usos da terra neste segmento.

Em uma observação mais atenta aos perfis dos vales conferidos pelos transectos, ao perfil longitudinal do rio Benevente (Figura 3), e aos aspectos morfoestruturais da área estudada, pode-se constatar alguns aspectos específicos que regulam a sua morfodinâmica.

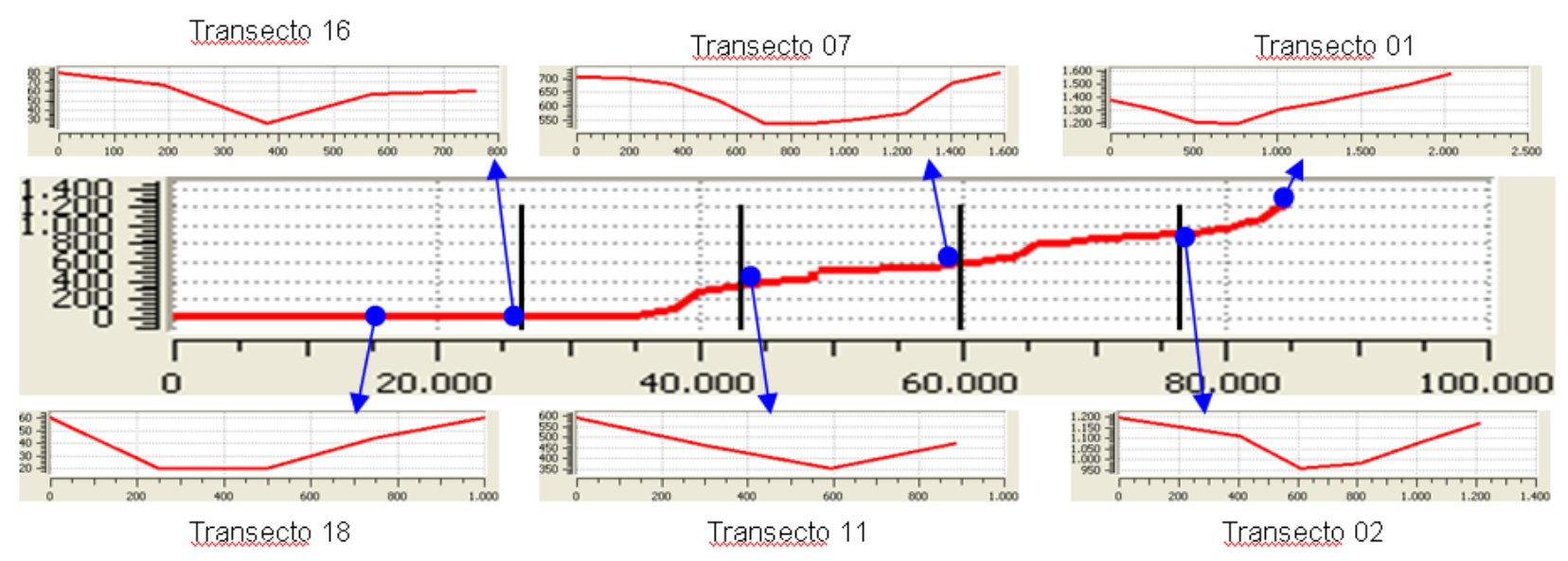

Figura 3 - Traçado do perfil Longitudinal do rio Benevente e transectos transversais situados nos limites das Unidades Geomorfológicas / Modelados. 
Os transectos 1 a 3 apresentam valores altos para D (Distância entre as médias das alturas dos interflúvios ao fundo dos vales), entretanto, o perfil longitudinal do rio Benevente para estes segmento demonstra uma baixa dissecação dos vales, principalmente porque nas proximidades das cabeceiras o fluxo fluvial apresenta um volume de água mais reduzido, não havendo muita capacidade de entalhamento. Nestes transectos, as profundidades aparentes dos vales dão-se mais pela altura dos interflúvios, elevados por constituírem parte dos granitóides do Maciço do Aracê, que constitui um corpo plutônico intrudido em meio ao Complexo Paraíba do Sul, e que integra a unidade Suíte Intrusiva Espírito Santo. Ocorrem associados a estas formações trechos de rochas aflorantes e solos rasos dado pela pequena profundidade de alteração das rochas.

Dos transectos 3 até 10, observa-se a dissecação dos vales, bem como os direcionamentos da drenagem, orientadas pelo controle estrutural dos lineamentos de falhas e das falhas intercruzadas (definindo grandes segmentos de rios encaixados), além dos trechos encachoeirados que decorrem dos desníveis escarpados dos blocos falhados e bascularizados para leste que integram o patamar oriental da Unidade dos Patamares Escalonados do Sul Capixaba. O controle estrutural conferido pelos gnaisses e kinzigitos do Complexo Paraíba do Sul promove grande influência sobre a esculturação do relevo, que se apresenta com grandes formas alongadas e pontões rochosos aflorantes, presenciando-se mantos de alteração pouco profundos (inferior a 2 metros), e grandes conjuntos de blocos rochosos (matacões) nas superfícies das encostas. Nos depósitos coluviais à base das elevações, tem-se a ocorrência de encostas compostas por espessas formações de Latossolos e Argisolos em declives que variam de 17 a 48 \%, onde se presenciam feições associadas a movimentos de massa e a ravinamentos, resultantes dos processos de desmatamento da floresta original e do uso inadequado do solo.

Os transectos 11 a 13 ocorrem no limite entre as Unidades Geomorfológicas da Região da Mantiqueira Setentrional, envolvendo trecho da Unidade Maciços do Caparaó, em segmento de forte desnível dado por deslocamento de blocos falhados e formações escarpadas, originando trechos fortemente encachoeirados e vales profundos com valores de D atingindo 430 metros. Este segmento apresenta-se bastante acidentado, com encostas de declive que atingem $75 \%$, caracterizando-se como declividades muito fortes. Neste ponto de contato entre as Unidades dos Patamares Escalonados do Sul Capixaba e Maciços do Caparaó, ocorre uma forte instabilidade das encostas em decorrência da rarefação da cobertura vegetal do tipo de material resultante da alteração das rochas, bastante susceptível à ação das águas superficiais.

Os transectos 16 a 18, situados na Unidade Geomorfológica Colinas e Maciços Costeiros, apresentam vales pouco incisos, com profundidade entre 50 e 40 metros, e vertentes com declividades fracas, variando 


\section{OS DESAFIOS DA GEOGRAFIA FÍSICA NA FRONTEIRA DO CONHECIMENTO \\ Instituto de Geociências - Unicamp \\ Campinas - SP \\ 28 de Junho à 02 de Julho de 2017}

entre 6 a 16\%. Os tipos de modelados de dissecação compreendem colinas convexas e/ou côncavoconvexas, separadas por depressões alveolares colmatadas e planícies aluviais.

Os transectos 19 e 20 ocorrem na Unidade das Planícies Litorâneas, constituída de material acumulativo aluvial e coluvial, recebendo influência marinha na proximidade do litoral na formação dos mangues, que atingem vários quilômetros para o interior do rio Benevente. As porções internas dos transectos apresentam uma superfície longa e plana, com declives muito fracos, inferiores a $6 \%$. Os interflúvios, de alturas geralmente inferiores a 40 metros, mormente ocorrem nas Unidades Colinas e Maciços Costeiros, e Tabuleiros Costeiros, e apresentam encostas de declives fracos a muito fracos, onde os processos erosivos podem ser facilmente controlados mediante o emprego de técnicas de manejo sustentáveis. Interna a própria Unidade encontram-se modelados de acumulação fluvial, sendo praticamente nula a produção de sedimentos.

Em uma análise geral, constata-se que os segmentos do curso superior do rio Benevente apresentam quadros de relevos mais acidentados, dotados de interflúvios de dimensões mais pronunciadas e de maiores declives nas encostas. Tal conformação limita o uso mais intensivo da terra, e apresenta uma maior necessidade de práticas sustentadas de intervenção, já que apresentam potencialidades morfodinâmicas mais intensas. A indicação de uso mais adequada para estas áreas, abarcando os segmentos até o transecto 13 , recai majoritariamente sobre a preservação e/ou recuperação da vegetação nativa, servindo de proteção contra os processos erosivos e de movimentação que se desencadeiam nos sistemas encostas, e propiciando a perenidade dos mananciais ao promover a recarga dos aquíferos nas cabeceiras de drenagem.

A redução nas altitudes e nas declividades das vertentes no médio curso, conjuntamente a uma maior presença de fundos de vales colmatados que integram formações alveolares, favorece o desenvolvimento das práticas antrópicas, e o assentamento de ocupações humanas, contudo, ainda exige a adoção de manejos adequados no uso do solo nas encostas, para evitar o desenvolvimento de processos erosivos, e o cuidado na ocupação das áreas das planícies intermontanas em decorrência dos efeitos das inundações periódicas, respeitando a preservação das formações vegetais ciliares.

Por sua vez, os segmentos do curso inferior, a partir do transecto 18, requerem uma menor atenção aos processos erosivos sobre as encostas (que devem incidir com maior ênfase sobre os modelados da Unidade dos Patamares Escalonados do Sul Capixaba, situados a sudoeste, e da Unidade dos Tabuleiros Costeiros a nordeste), por apresentarem grandes extensões de áreas planas e/ou de baixas declividades que caracterizam a planície fluvial litorânea. Por ser a unidade geomorfológica mais favorável à ocupação humana, é onde esta ocorre de modo mais intenso, decorrente tanto do contexto inerente às características 


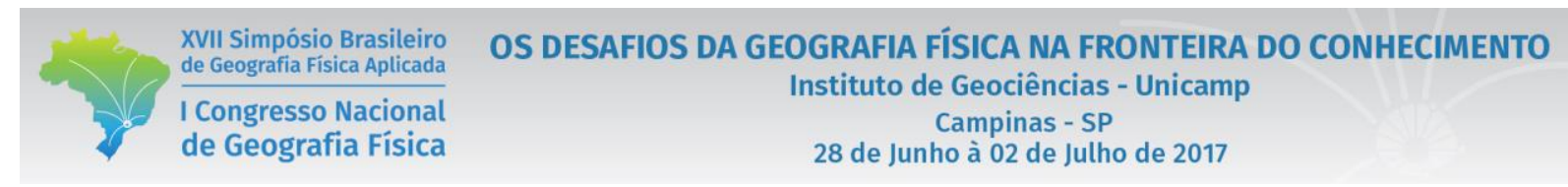

daquele sítio, quando pelo fator histórico de ocupação do território capixaba. Entretanto, do ponto de vista geomorfológico, não obstante as obras de drenagem executadas pelo DNOS na década de 1970, exige grande cuidado de uso nas porções próximas ao curso fluvial, e nos tipos de interferências causadas sobre este último, seja pelas possibilidades de inundações, seja pela deflagração de desequilíbrios no canal, capazes de ativar processos erosivos locais e de repercussão remontante.

\section{Considerações finais}

Os dados morfométricos e as informações morfológicas analisadas ao longo do curso do rio Benevente indicam uma maior demanda nos cuidados com o uso da terra e a cobertura do solo nas áreas de montante, onde o relevo apresenta-se com declives mais acentuados e com maiores condições de instabilidade. Conforme o esperado, isto reforça as questões tratadas em variados estudos de que a utilização de faixas vegetadas de natureza ciliar aos cursos d'água podem não ser suficientes para a proteção dos sistemas fluviais. Na situação dos relevos planálticos do Sudeste brasileiro, principalmente os segmentos montanhosos e acidentados dos conjuntos de blocos falhados e escarpados, é necessário ainda um forte controle sobre os usos e processos que se desenvolvem nas encostas, entendendo que estas é que fornecem materiais detríticos que causam alterações na dinâmica dos sistemas fluviais. Notoriamente, a causa destas alterações, por incremento da carga sedimentar aos cursos d'água, reportam às áreas mais elevadas e mais acidentadas da bacia de drenagem, onde a potencialidade de produção de sedimentos tende a ser maior, reiterando a conclusão de que a proteção dos sistemas fluviais em uma bacia hidrográfica possui maior apelo no sentido das áreas planas para as montanhosas, e de jusante para montante.

\section{Bibliografia}

ATTANASIO, C. M. et al. Método para a identificação da zona ripária: microbacia hidrográfica do Ribeirão São João (Mineiros do Tietê, SP). Scientia Florestalis, n. 71, p. 131-140, ago. 2006.

COSTA, José Mario Leal Martins. Estudo teórico sobre meios de determinação de Áreas de Preservação Permanente (APPs) marginais aos cursos d'água através da análise de fatores ambientais no âmbito da bacia hidrográfica: enfoque geomorfológico. 2010. 170f. Dissertação (Mestrado em Geografia) - Universidade Estadual do Rio de Janeiro, Rio de Janeiro, 2010.

. Áreas de preservação permanente e indicativos teóricos para a proteção de sistemas fluviais. In: Simpósio Brasileiro de Geografia Física Aplicada, 15, 2013, Vitória. Anais... Vitória: UFES, 2013.

CPRM. Site institucional. Disponível em: < http://www.cprm.gov.br/\#>. Acesso em 20 jul. 2016.

FLORENZANO, Teresa G. Introdução à geomorfologia. In: FLORENZANO, Teresa Gallotti (org.).

Geomorfologia: conceitos e tecnologias atuais. São Paulo: Oficina de textos, 2008. p. 11-30.

GUERRA, Antonio José Teixeira. Novo dicionário geológico-geomorfológico. 4. ed. Rio de Janeiro: Bertrand Brasil, 2005. $652 \mathrm{p}$ 
IEMA. Site institucional. Disponível em: < https://iema.es.gov.br/>. Acesso em 10 fev. 2016.

MACHADO, Ronalton Evandro. Simulação de escoamento e de produção de sedimentos em uma microbacia hidrográfica utilizando técnicas de modelagem e geoprocessamento. 2002. 154 f. Tese (Doutorado em Agronomia) - Escola Superior de Agricultura Luiz de Queiroz, Universidade de São Paulo, Piracicaba, 2002.

MOMOLI, Renata Santos. Caracterização espacial dos sedimentos depositados numa zona ripária reflorestada. 2006. 107 f. Dissertação (Mestrado em Agronomia) - Escola Superior de Agricultura Luiz de Queiroz, Universidade de São Paulo, Piracicaba, 2006.

MORO, Michele. A utilização da interface SWAT-SIG no estudo da produção de sedimentos e do volume de escoamento superficial com simulação de cenários alternativos. 2005. 100 f. Dissertação (Mestrado em Agronomia) - Escola Superior de Agricultura Luiz de Queiroz, Universidade de São Paulo, Piracicaba, 2005.

RADAMBRASIL. Folhas SF.23/24 Rio de Janeiro/Vitória: geologia, geomorfologia, pedologia, vegetação e uso potencial da terra. Projeto RADAMBRASIL: Rio de Janeiro, 1983.

ROSS, Jurandir L. S. Geomorfologia aplicada aos EIAs-RIMAs. In: GUERRA, Antônio J. T.; CUNHA, Sandra B. da (org.). Geomorfologia e meio ambiente. 4. ed. Rio de Janeiro: Bertrand Brasil, 2003. p. 291-336. 